chapters. I counted half a dozen references which were reproduced in triplicate and many papers that were quoted twice by different authors. Perhaps it emphasizes the rather specialized nature of the book. There are several typographical errors, in particular the dose of total body irradiation is given as $100 \mathrm{rad}$ instead of $1000 \mathrm{rad}$ in the table on page 136. There were numerous misprints of authors' names and initials throughout the references. I think it is a pity that Dr Geary did not think it worth-while including a chapter on other approaches to treatment in this disease: the use of stimulators such as androgens, lithium, etiocholanolone and PHA merit some attention since they point to methods other than immunosuppression and bone marrow transplantation whereby aplastic bone marrow can be stimulated to regenerate.

All in all, this is an up-to-date and comprehensive review of a fascinating subject which provides good reading and an excellent source of references for the haematologist or physician involved with the investigation and management of aplasia and its related syndromes. The book makes good reading for Final M.R.C.Path. at a price which is not unreasonable these days.

\section{Biochemical Disorders of the Skeleton}

By Roger Smith. Postgraduate Orthopaedics Series. Series Editor: A. GrahaM APLeY. Pp. $x+293$, illustrated. Butterworths, London, 1979. $£ 19.50$.

This book is primarily intended for orthopaedic surgeons and others involved in the clinical and laboratory techniques and management of bone disease. The author correctly notes that it is not intended as a text on 'metabolic bone disease' and rather disarmingly expresses the hope that it will be of help to orthopaedic surgeons who find the subject made 'needlessly complex by physicians'.

The text is concise, perhaps reflecting the series of postgraduate lectures on which it is based. The first 2 chapters present an up-to-date review of bone physiology and the diagnosis of metabolic bone disorders. Subsequent sections are devoted to the topics of osteomalacia, osteoporosis, parathyroids in relation to bone disease and ectopic mineralization. The remainder deal with disease entities including Paget's disease, osteogenesis imperfecta, Marfan's and related syndromes and the mucopolysaccharidoses. The final 2 chapters are concerned with a miscellany of rarer conditions and recent advances respectively. The book is adequately illustrated although many of the diagrams will be familiar to those already working in the field. It is, however, extremely well provided with selected, up-to-date references.

The book can be recommended as a useful introduction to the subject, particularly for those preparing for postgraduate examinations. It would also provide a useful and readable review for surgeons and other clinicians in the field. In spite of its price, it will be a useful addition to postgraduate libraries.

\section{A Colour Atlas of Liver Disease}

By Sheila Sherlock and John A. Summerfield. Pp. 272, illustrated. Wolfe Medical Publications, London, 1979. £18.00.

This is an outstanding collection of more than 500 illustrations encompassing the whole spectrum of liver disease. Rare diseases, paediatric and tropical diseases are all covered. In addition to the many clinical photographs, relevant histology, isotope scans, CT scans, ultrasounds, X-rays, endoscopies and laparoscopies are all included. The quality of the illustrations is generally very good although some of the X-rays have not reproduced well. The legends to the illustrations are particularly useful, the reader often being reminded of the causes and pathophysiology of the abnormality. The book will undoubtedly be of value to any physician with an interest in liver disease.

\section{Controlling the Smoking Epidemic}

Report of the WHO Expert Committee on Smoking Control. WHO Technical Report Series no. 636. Pp. 87, illustrated. World Health Organization, Geneva, 1979. Sw. fr. 9.00.

This excellent small monograph is the report of the WHO Expert Committee on Smoking Control. It deals with the harmful health consequences of smoking, particularly emphasizing the statistics in relation to ischaemic heart disease, chronic bronchitis and emphysema and neoplasia of the lung, and the effects of smoking on children and young people. The socio-economic implications of tobacco smoking entails huge economic losses which constitute a sizable burden to every national economy. Of particular interest are the recommended strategies for controlling the smoking epidemic and also monitoring the smoking problem.

This is an excellent monograph and should be compulsory reading for all doctors and smokers. It is very reasonably priced and will, it is hoped, enjoy a wide circulation.

\section{Human Growth}

Edited by Frank Falkner and J. M. Tanner. Vol. Principles and Prenatal Growth. Pp. xix +634 , illustrateo

Vol. 2. Postnatal Growth. Pp. xviii +634 , illustrated Baillière Tindall, London, 1978. £24.75 per vol.

The phenomenon of growth has intrigued physicians ane laymen alike for centuries and yet it is only recently that itg study has become the subject of major interdisciplinare scientific endeavour. Few attempts have been made to relate the wide range of fields of investigation to each othes ranging as they do from prenatal to adolescent life, fron experimental biology to clinical medicine and from the growth of cells in individual tissues to the complex mechanisms governing growth and maturation of the intact organism.

This series of 3 volumes, of which the first 2 have now been published, are a remarkable attempt to remedy this gap in the literature. They contain contributions from nearly 70 distinguished workers under the editorship of 2 acknowledged experts. The first volume is concerned with the principles of human developmental biology, the application of biometrical methods, the genetics of growth and growth in the prenatal period. The second volume is devoted to postnatal growth from infancy to adolescence, with sections on anthropometry, hormonal and compositional changes, dentition, and the growth of low birth weight infants. Each volume is well illustrated and referenced and is separately indexed.

This series will provide a valuable reference source for research workers, obstetricians, paediatricians and others involved in child health and development. The price is a little high but not excessive for what may well become a standard work.

The Investigation of the Surgical Patient

By F. G. Smiddy. Pp. $x+262$, illustrated. Edward Arnold, London, 1979. £17.50.

Geoffrey Smiddy is a Leeds surgeon, born and bred in the Moynihan tradition and continues to carry his torch as a magnificent surgical teacher. In this, his third major text- 